\title{
Study on the Removal Performance of Phenol and Lead by Vernadite Synthesized via a New Method
}

\author{
Baibing Wang $\mathbb{D}^{D}$, Nanqi Ouyang $\mathbb{D}$, Qin Zhang $\mathbb{D}^{\mathbb{D}}$, Shizhang Zheng $\mathbb{D}$, Yang Li $(\mathbb{D}$, \\ Zhangjie Qin $(\mathbb{D}$, Mimi Luo $\mathbb{D}$, and Guanjie Jiang $(\mathbb{D})$
} Key Laboratory of Poyang Lake Watershed Agricultural Resources and Ecology of Jiangxi Province, College of Land Resources
and Environment, Jiangxi Agricultural University, Nanchang 330045, China

Correspondence should be addressed to Guanjie Jiang; jiangguanjie@126.com

Received 8 June 2021; Accepted 25 July 2021; Published 19 August 2021

Academic Editor: Huihui Du

Copyright (C) 2021 Baibing Wang et al. This is an open access article distributed under the Creative Commons Attribution License, which permits unrestricted use, distribution, and reproduction in any medium, provided the original work is properly cited.

\begin{abstract}
Vernadite has excellent oxidation and adsorption performance, suggesting that it has good application prospects for the removal of phenolic substances and heavy metals from wastewater. In this study, after vernadite was synthesized by two different methods, the removal performance difference between the samples synthesized by the new and traditional methods (Ver- $\mathrm{H}$ and Ver-OH, respectively) was explored by sample characterization, phenol degradation, and $\mathrm{Pb}^{2+}$ adsorption experiments. The results show that, compared with Ver-OH, Ver-H has a larger particle size, specific surface areas, and total organic carbon (TOC) degradation capacity; the equilibrium degradation capacity of TOC of Ver-H was increased by $31.3 \%$. The difference in the amount of TOC degradation may be attributed to more $\mathrm{Mn}$ (IV) oxygen vacancies in Ver-H, which facilitate the removal of intermediate products formed during phenol degradation. In addition, the larger specific surface areas provide the mineral surface with a larger number of active sites; Ver-H can therefore adsorb more intermediate products to promote their mineralization into $\mathrm{CO}_{2}$. The adsorptions of $\mathrm{Pb}^{2+}$ by Ver-H and Ver-OH are both consistent with Langmuir isothermal adsorption, and the maximum adsorption capacities are $569.79 \mathrm{~g} / \mathrm{kg}$ and $623.10 \mathrm{~g} / \mathrm{kg}$, respectively. The lack of significant difference indicates that both vernadites have strong adsorption capacities for $\mathrm{Pb}^{2+}$.
\end{abstract}

\section{Introduction}

Manganese oxides are widely distributed in the environment as important components of soil and sediments, with additional prevalence in oceans, rivers, and lakes. Owing to their high activity, catalytic efficiency, low toxicity, and abundance, they are widely used in the fields of adsorption and oxidative degradation, as well as in capacitors [1-6]. Vernadite is a layered manganese oxide commonly found in nature; it is formed by the close hexagonal accumulation of oxygen ions and water molecules [7]. It has a high specific surface area, structural defects, and a mixed valence state of $\mathrm{Mn}[8$, 9] and plays a pivotal role in the biogeochemical cycle of metals and carbon. It is often used as a heavy metal adsorbent and oxidant for various organic and inorganic pollutants. For example, Zhang et al. [10] studied the adsorption and oxida- tion differences of vernadite with different $\mathrm{Mn}$ average oxidation states $\left(\mathrm{Mn}_{\mathrm{AOS}}\right)$ on As and $\mathrm{Cr}$, demonstrating that the $\mathrm{Mn}_{\mathrm{AOS}}$ determines the oxidation capacity of vernadite on As to a certain extent. Higher $\mathrm{Mn}_{\mathrm{AOS}}$ corresponds to greater As oxidation capacity; however, its influence on $\mathrm{Cr}$ is small. Dong et al. [11] studied the removal effect and mechanism of vernadite toward phenol under different experimental conditions. The results showed that vernadite has a strong phenol removal effect, and the removal mechanism is adsorption and oxidation, with $\mathrm{pH}$ being the most influential factor. When the $\mathrm{pH}$ was lower than 4 , oxidation dominated; at $\mathrm{pH}$ exceeding 4 , the removal of phenol was mainly due to vernadite adsorption.

Vernadite has a poorly crystalline lamellar structure that is unstable in the environment and easily aged into other $\mathrm{Mn}$ ores. Therefore, few reports exist regarding the application 
and synthesis of vernadites. At present, the main synthetic method for vernadite is the redox method [12-14]. $\mathrm{Mn}^{2+}$ is oxidized by $\mathrm{MnO}_{4}{ }^{-}$at room temperature under weakly alkaline conditions to eventually form vernadite.

In consideration of the complexity and high cost of this traditional synthesis method, a simpler and more economical method is adopted in this study: $\mathrm{KMnO}_{4}$ is used to oxidize $\mathrm{H}_{2} \mathrm{O}_{2}$ under acidic conditions to synthesize vernadite. After the physical properties of vernadite synthesized by these two methods were compared, the removal performance of vernadite for phenol, TOC, and $\mathrm{Pb}^{2+}$ was investigated.

\section{Materials and Methods}

2.1. Reagents and Water. All chemical reagents required for the experiment were of analytical grade, and ultrapure water was used in the experiment.

\subsection{Vernadite Preparation}

2.2.1. Preparation of Vernadite by the New Method. First, $10.0000 \mathrm{~g} \mathrm{KMnO}_{4}$ was weighed in a $500 \mathrm{~mL}$ conical flask. Next, $300 \mathrm{~mL}$ ultrapure water and $1.75 \mathrm{~mL}$ of $98 \%$ concentrated $\mathrm{H}_{2} \mathrm{SO}_{4}$ were added with a magnetic stirrer for dissolution in acidic conditions; then, $100 \mathrm{~mL}$ of $\mathrm{H}_{2} \mathrm{O}_{2}(1.17 \mathrm{~mol} / \mathrm{L})$ was added dropwise to the $\mathrm{KMnO}_{4}$ solution at a speed of $5 \mathrm{~mL} / \mathrm{min}$. After standing for $30 \mathrm{~min}$, the supernatant was poured out, and the collected solid was washed with deionized water until the conductivity of the filtrate was lower than $20 \mu \mathrm{s} / \mathrm{cm}$. The solid was freeze-dried, ground, and sieved to 100 mesh for later use. The obtained sample was named Ver-H.

2.2.2. Preparation of Vernadite by Traditional Methods. According to the methods described by Catts and Langmuir [15] and Luo et al. [16], vernadite was synthesized by oxidizing $\mathrm{Mn}^{2+}$ with $\mathrm{KMnO}_{4}$ under alkaline conditions. (1) Firstly, three solutions of $\mathrm{A}, \mathrm{B}$, and $\mathrm{C}$ were configured: $75.14 \mathrm{~g}$ $\mathrm{MnCl}_{2} \cdot 4 \mathrm{H}_{2} \mathrm{O}$ was weighed and dissolved in $1280 \mathrm{~mL}$ ultrapure water, which was set as $\mathrm{A} ; 40.00 \mathrm{~g} \mathrm{KMnO}_{4}$ was treated as the above methods named solution $\mathrm{B} ; 28 \mathrm{~g}$ of $\mathrm{NaOH}$ was weighed and dissolved by addition of $1440 \mathrm{~mL}$ of ultrapure water as solution C. (2) Then, solution B was slowly added into solution $\mathrm{C}$ within 5 minutes with stirring. After that, solution A was added slowly to the above mixed solution in 35 minutes with stirring, which showed a black color. (3) The supernatant of the suspension was poured after standing for 4 hours, and the left suspension was centrifuged and the residue was collected. (4) The residue was washed with $1 \mathrm{~mol} / \mathrm{L} \mathrm{NaCl}$ solution for 5 times and shook overnight at the last time. (5) Finally, the solid was washed until the supernatant conductance was less than $20 \mu \mathrm{s} / \mathrm{cm}$ and the $\mathrm{pH}$ was about 6.2. The sample was freeze-dried, ground, and sieved to 100 mesh for later use. The sample is named Ver-OH.

2.3. Sample Characterization. The X-ray powder diffraction (XRD) patterns of the prepared samples were determined using a D8 ADVANCE polycrystalline X-ray diffractometer equipped with $\mathrm{Cu} \mathrm{K} \alpha$ radiation at a voltage of $35 \mathrm{kV}$ and current of $38 \mathrm{~mA}$. The scan range was from $5^{\circ}$ to $85^{\circ}$. The mor- phology of the samples was determined by field-emission scanning electron microscopy (SEM) using a Czech Fei Nova NanoSEM450 microscope. The working voltage was $10 \mathrm{kV}$. Fourier-transform infrared spectroscopy (FTIR) was performed using an INVENIO S spectrometer. The test range was $4000-400 \mathrm{~cm}^{-1}$. Thermogravimetric (TG) analysis was performed using a Germany Netzsch STA409PC synchronous thermal analyzer in the temperature range $30-930^{\circ} \mathrm{C}$ at a heating rate of $10^{\circ} \mathrm{C} / \mathrm{min}$. The specific surface areas (SSAs) of the samples were measured using an automatic specific surface and pore size distribution analyzer (Micromeritics ASAP 2020) and calculated using the BrunauerEmmett-Teller (BET) theory. The $\mathrm{Mn}_{\mathrm{AO}}$ was determined using the oxalic acid method [5]. The chemical composition of the samples was determined according to Catts and Langmuir [15].

2.4. Phenol Degradation. Vernadite powder $(0.0625 \mathrm{~g})$ was placed in a $250 \mathrm{~mL}$ triangular flask, to which $100 \mathrm{~mL}$ of ultrapure water was added before the flask was placed in a magnetic mixer for suspension stirring. The $\mathrm{pH}$ of the mineral suspension was adjusted to 3.00 with $0.1 \mathrm{~mol} / \mathrm{L} \mathrm{HCl}$ and $0.1 \mathrm{~mol} / \mathrm{L} \mathrm{NaOH}$ until the $\mathrm{pH}$ value fluctuated by less than 0.05 within $24 \mathrm{~h}$. After $\mathrm{pH}$ stabilization, the sample suspension was transferred to a $250 \mathrm{~mL}$ double-layer beaker and $25 \mathrm{~mL}$ of a $500 \mathrm{mg} / \mathrm{L}$ phenol solution was added. After the above treatment, the vernadite concentration was $0.5 \mathrm{~g} / \mathrm{L}$ and the initial concentration of phenol was $100 \mathrm{mg} / \mathrm{L}$. The phenol degradation reaction was performed at $25^{\circ} \mathrm{C}$ with agitation. According to the set time gradient, $15 \mathrm{~mL}$ of the reaction solution was sampled each time and filtered through a $0.22 \mu \mathrm{m}$ microporous membrane to obtain the test solution, from which the concentrations of phenol and TOC were determined in the later period. Two parallel samples were used for each group, and the results were averaged.

The phenol concentration was determined by highperformance liquid chromatography (HPLC, Agilent 1260). The basic test parameters were as follows: fluorescence detector, excitation wavelength $270 \mathrm{~nm}$, emission wavelength $300 \mathrm{~nm}$; C18 column, column temperature $25^{\circ} \mathrm{C}$; mobile phase volume (acetonitrile): pure water volume $=30: 70$; flow rate $0.3 \mathrm{~mL} / \mathrm{min}$; injection volume $5 \mu \mathrm{L}$. The TOC concentration was measured using a TOC analyzer (multi N/C 3100 TOC in Jena, Germany).

2.5. $\mathrm{Pb}^{2+}$ Isothermal Adsorption. In the adsorption experiment, $0.7500 \mathrm{~g}$ of vernadite and $1.75 \mathrm{~g}$ of $\mathrm{NaNO}_{3}$ were weighed in a $250 \mathrm{~mL}$ triangular flask. After adding $150 \mathrm{~mL}$ of ultrapure water, the mixture was suspended and stirred on a magnetic stirrer to prepare a sample suspension of $5 \mathrm{~g} / \mathrm{L}$. The suspension $\mathrm{pH}$ was adjusted to 4.50 with 0.1 mol/ $\mathrm{L} \mathrm{HNO}_{3}$ and $0.1 \mathrm{~mol} / \mathrm{L} \mathrm{NaOH}$ until the $\mathrm{pH}$ value did not fluctuate by more than 0.05 within $24 \mathrm{~h}$. A series of $\mathrm{Pb}\left(\mathrm{NO}_{3}\right)_{2}$ solutions $(0,1,2,3,4,5,6,7$, and $8 \mathrm{~mL})$ were added into the centrifugal tubes, the volume was corrected to $10 \mathrm{~mL}$ with $0.15 \mathrm{~mol} / \mathrm{L} \mathrm{NaNO}_{3}$, and then, $5 \mathrm{~mL}$ vernadite suspension was added. The centrifuge tube was kept in an oscillator at $25 \pm 1^{\circ} \mathrm{C}$ at a speed of $250 \mathrm{rpm}$ for $24 \mathrm{~h}$. The $\mathrm{pH}$ of the system was adjusted to $4.50 \pm 0.05$ twice with $0.1 \mathrm{~mol} / \mathrm{L} \mathrm{HNO}_{3}$ 
and $\mathrm{NaOH}$ during the reaction process, and the amount of $\mathrm{HNO}_{3}$ and $\mathrm{NaOH}$ solution added was recorded. After reacting for $24 \mathrm{~h}$, the supernatant was filtered through a $0.22 \mu \mathrm{m}$ filter membrane. The equilibrium concentration of $\mathrm{Pb}^{2+}$ in the supernatant was analyzed using an atomic absorption spectrometer (Agilent AAS240FS), and the adsorption capacity of $\mathrm{Pb}^{2+}$ was calculated. The above experiment was repeated three times, and the results were averaged.

\subsection{Data Analysis}

2.6.1. Langmuir Isothermal Adsorption Equation. To understand the adsorption behavior of vernadite toward heavy metal ions, the Langmuir isothermal adsorption equation was used to fit the adsorption process of $\mathrm{Pb}^{2+}$ by vernadite. The equation is as follows:

$$
Q=\frac{A K_{1} C}{1+K_{1} C},
$$

where $Q$ is the adsorption capacity of vernadite per unit weight to $\mathrm{Pb}^{2+}(\mathrm{g} / \mathrm{kg}), A$ is the maximum adsorption capacity of $\mathrm{Pb}^{2+}(\mathrm{g} / \mathrm{kg}), K_{1}$ is a constant related to the adsorption binding energy, and $C$ is the concentration of $\mathrm{Pb}^{2+}$ in the equilibrium solution $(\mathrm{mg} / \mathrm{L})$.

2.6.2. Dynamic Equation. To understand the chemical behavior of vernadite in degrading phenol, a pseudo-second-order kinetic equation was used in this study to linearly fit the kinetic curve of vernadite toward phenol degradation in $12 \mathrm{~h}$. The pseudo-second-order kinetic equation is as follows:

$$
\frac{t}{q_{t}}=\frac{1}{k_{2} q_{e}^{2}}+\frac{t}{q_{e}},
$$

where $q_{e}$ and $q_{t}$ are the removal amounts (mg/g) at equilibrium $e$ and at time $t$, respectively, and $k_{2}$ is the rate constant $(\mathrm{mg} /(\mathrm{g} \cdot \mathrm{h}))$ of the pseudo-second-order equation. The rate constant $k_{2}$ and correlation coefficient $R^{2}$ were obtained by fitting.

\section{Results and Discussions}

3.1. XRD Analysis. The XRD patterns of the synthesized samples are shown in Figure 1. The two spectral lines are similar with diffraction peaks at $37^{\circ}$ and $66^{\circ}$, representing the $(11,20)$ and $(31,02)$ crystal plane diffraction peaks of vernadite, respectively, which is consistent with the relevant literature $[17,18]$. As shown in the figure, the diffraction peaks of the synthesized minerals are low in intensity with broad halfpeak widths, indicating that the minerals synthesized by the new method are structurally consistent with those synthesized by the traditional method, both of which are pure and slightly crystallized vernadite.

3.2. SEM Analysis. SEM images of the vernadite synthesized by the two methods are shown in Figure 2. It can be seen clearly from the figure that the structures of the two minerals are well distributed, while the morphologies differ. The morphology of Ver-H is nanosheet-like, whereas Ver-OH is

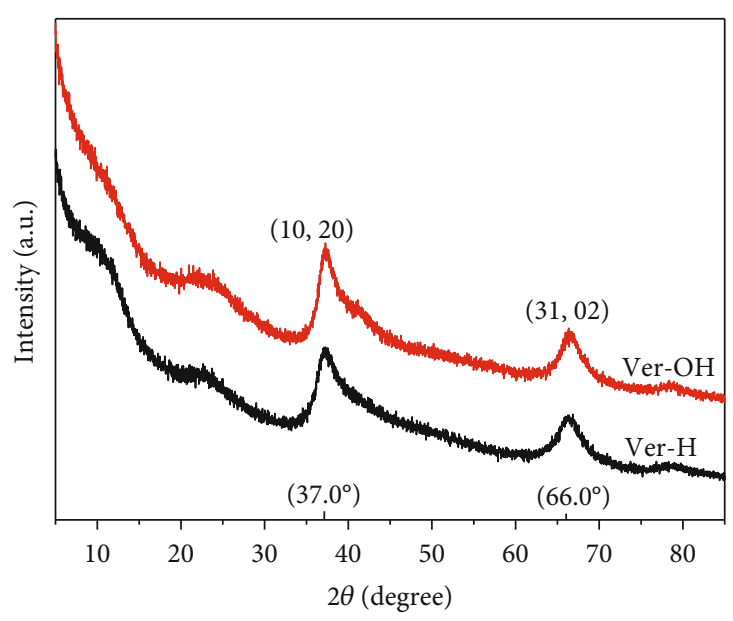

FIGURE 1: XRD spectra of vernadite samples.

granular. The particle size of Ver-H is somewhat larger than that of Ver-OH. Both crystals show obvious aggregation, with greater agglomeration in the particles of Ver-OH. The above results show that the vernadite synthesized by the new method has increased particle size and morphological changes.

3.3. TG Analysis. No significant difference appears between the TG curves of Ver-H and Ver-OH (Figure 3). The total weight losses of Ver-H and Ver-OH are $24.19 \%$ and $23.69 \%$, respectively, and both have three obvious weight loss peaks. The rapid and large weight loss of the two samples before $300^{\circ} \mathrm{C}$ mainly originates from surface-adsorbed water and water molecules located between the octahedral layers of vernadite [19], indicating that both samples have high hygroscopicity. The weight loss in the range of $470-640^{\circ} \mathrm{C}$ may arise from the partial conversion of $\mathrm{MnO}_{2}$ to $\mathrm{Mn}_{2} \mathrm{O}_{3}$ in vernadite $[20,21]$. The final weight loss peaks of Ver-H and Ver$\mathrm{OH}$ differ significantly: the weight loss temperature of Ver$\mathrm{OH}\left(870-940^{\circ} \mathrm{C}\right)$ is significantly higher than that of Ver-H $\left(680-740^{\circ} \mathrm{C}\right)$. The weight losses of the two minerals at this temperature may be caused by the transformation of $\mathrm{Mn}_{2} \mathrm{O}_{3}$ to $\mathrm{Mn}_{3} \mathrm{O}_{4}[22,23]$. The results of the TG analysis showed that both Ver-H and Ver-OH had good thermal stability.

3.4. FTIR Analysis. The samples synthesized by the two methods were characterized by FTIR, as shown in Figure 4. The results show that the absorption bands of Ver-OH and Ver-H are similar, located at 3378, 1630, 920, 738, 585, and $550 \mathrm{~cm}^{-1}$. The band at $3378 \mathrm{~cm}^{-1}$ is due to the stretching vibration of free hydroxyl groups on the mineral surface, and that at $1630 \mathrm{~cm}^{-1}$ is caused by the $\mathrm{H}-\mathrm{O}-\mathrm{H}$ bending vibrations of water molecules, indicating that the synthesized minerals contain crystalline water $[24,25]$. The peak at $920 \mathrm{~cm}^{-1}$ can be attributed to the bending vibration of hydroxyl groups around the vacancy in the $\left[\mathrm{MnO}_{6}\right]$ layer [26]. The strength of this peak is slightly lower for Ver-H than for Ver-OH, indicating that the number of hydroxyl groups around the vacancy in Ver-H is lower than that in Ver-OH. Generally, the number of oxygen vacancies 


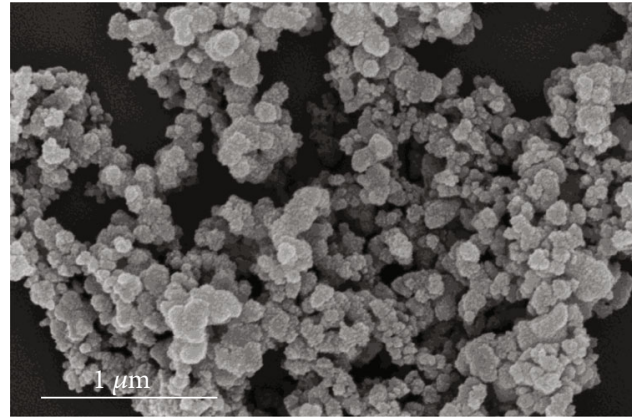

(a)

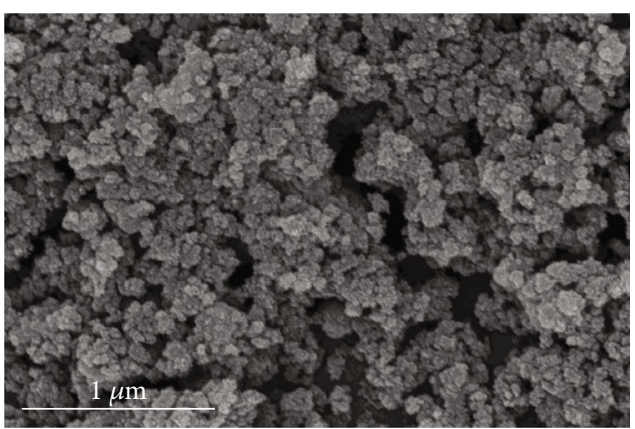

(b)

FIgURE 2: SEM images of vernadite: (a) Ver-H and (b) Ver-OH.

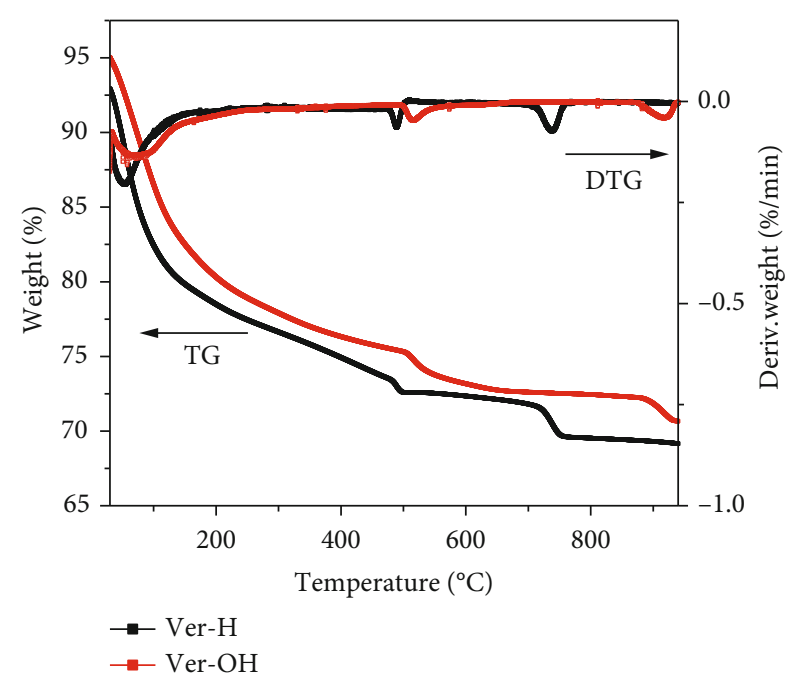

Figure 3: TG and differential TG spectra of vernadite samples.

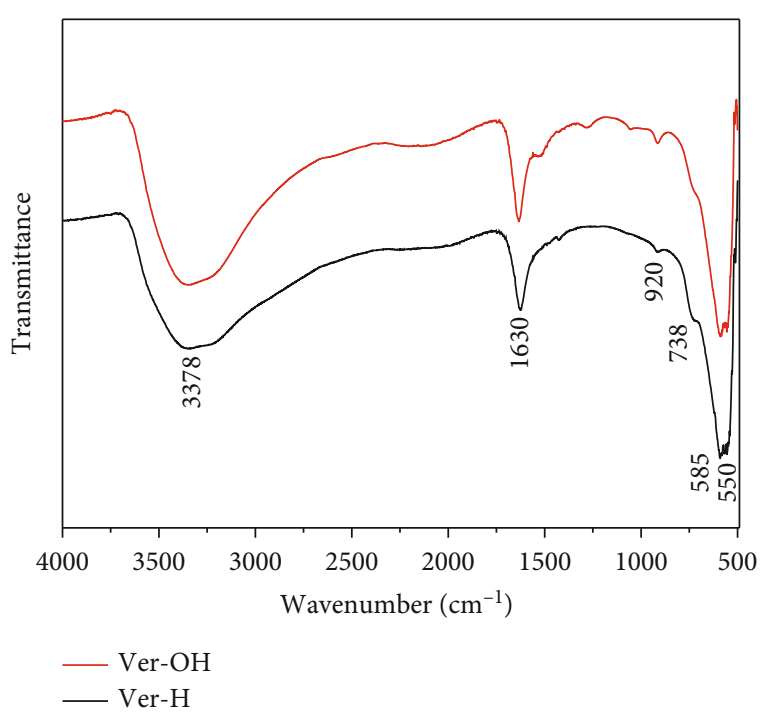

FIGURE 4: FTIR spectra of synthetic vernadites.

decreases with a decrease in $\mathrm{Mn}_{\mathrm{AOS}}$, which in turn affects the number of surrounding hydroxyl groups. Therefore, the $\mathrm{Mn}_{\mathrm{AOS}}$ of Ver-H may be lower than that of Ver-OH.
The absorption bands located at 738,585 , and $550 \mathrm{~cm}^{-1}$ may correspond to $\mathrm{Mn}-\mathrm{O}-\mathrm{Mn}$ stretching vibrations in the mineral [27].

3.5. $M n_{A O S}$, Chemical Composition, and SSAs. Data for the $\mathrm{Mn}_{\mathrm{AOS}}$, SSAs, and elemental contents of the synthetic vernadite samples are shown in Table 1. The chemical compositions of Ver-H and Ver-OH are similar, while the $\mathrm{Mn}_{\mathrm{AOS}}$ of Ver-H is lower than that of Ver-OH; this is consistent with the relevant conclusions from the FTIR spectra. The resulting difference in $\mathrm{Mn}_{\mathrm{AOS}}$ in Ver-OH and Ver-H may be related to the $\mathrm{K}$ content in the mineral [28]. The SSAs of Ver-H is increased compared to that of Ver-OH, possibly because of the agglomeration of smaller-sized particles in Ver-OH. The vernadite synthesized using the new method has a large SSAs.

3.6. Performance Comparisons of the Two Vernadites in Phenol Degradation. The corresponding phenol and TOC degradation rates, as well as the pseudo-secondary kinetic curves, were obtained from the kinetic experiments of phenol degradation by the two vernadites (Figure 5). As shown in Figures 5(a) and 5(e), the trends in the phenol degradation rates of Ver-H and Ver-OH are consistent. The degradation rate of phenol by both minerals reaches $45 \%$ after 3 minutes of the reaction, indicating that phenol is quickly removed after contact with vernadite. This may be due to the strong oxidation capacity and the large number of adsorption sites in vernadite, which can quickly oxidize and adsorb phenol. The phenol degradation rate is increased rapidly in the first 30 minutes of the reaction with increasing reaction time, and then, the increase rate decreases. This may be due to the occupation of almost all of the active sites on the surfaces of the two vernadites by phenol in the initial stages of the reactions. When $\mathrm{Mn}(\mathrm{IV})$ is reduced to $\mathrm{Mn}(\mathrm{III})$ and $\mathrm{Mn}(\mathrm{II})$, some of the low-valence $\mathrm{Mn}$ ions are adsorbed on the mineral surface. These ions compete with phenol and its intermediates, which inhibits further degradation of phenol. After $6 \mathrm{~h}$ of reaction, the degradation rate is constant, and the reaction reaches equilibrium. No significant difference in the phenol degradation rate is observed between Ver- $\mathrm{H}$ and Ver-OH during the reaction process, indicating that the vernadite synthesized by both methods has a strong degradation effect on phenol. The dynamic change pattern of TOC is similar to 
TABLE 1: $\mathrm{Mn}_{\mathrm{AOS}}$, SSAs, and chemical composition of vernadite samples.

\begin{tabular}{|c|c|c|c|c|c|}
\hline \multirow{2}{*}{ Sample name } & \multirow{2}{*}{$\mathrm{Mn}_{\mathrm{AOS}}$} & \multirow{2}{*}{ SSAs $\left(\mathrm{m}^{2} / \mathrm{g}\right)$} & \multicolumn{2}{|c|}{ Element content $(\%)$} & \multirow{2}{*}{ Chemical formula } \\
\hline & & & $\mathrm{Mn}$ & $\mathrm{K}$ & \\
\hline Ver-H & 3.71 & 173 & 47.95 & 1.05 & $\mathrm{~K}_{0.03} \mathrm{MnO}_{1.87}\left(\mathrm{H}_{2} 0\right)_{0.78}$ \\
\hline Ver-OH & 3.82 & 153 & 51.21 & 2.52 & $\mathrm{~K}_{0.06} \mathrm{MnO}_{1.94}\left(\mathrm{H}_{2} 0\right)_{0.65}$ \\
\hline
\end{tabular}
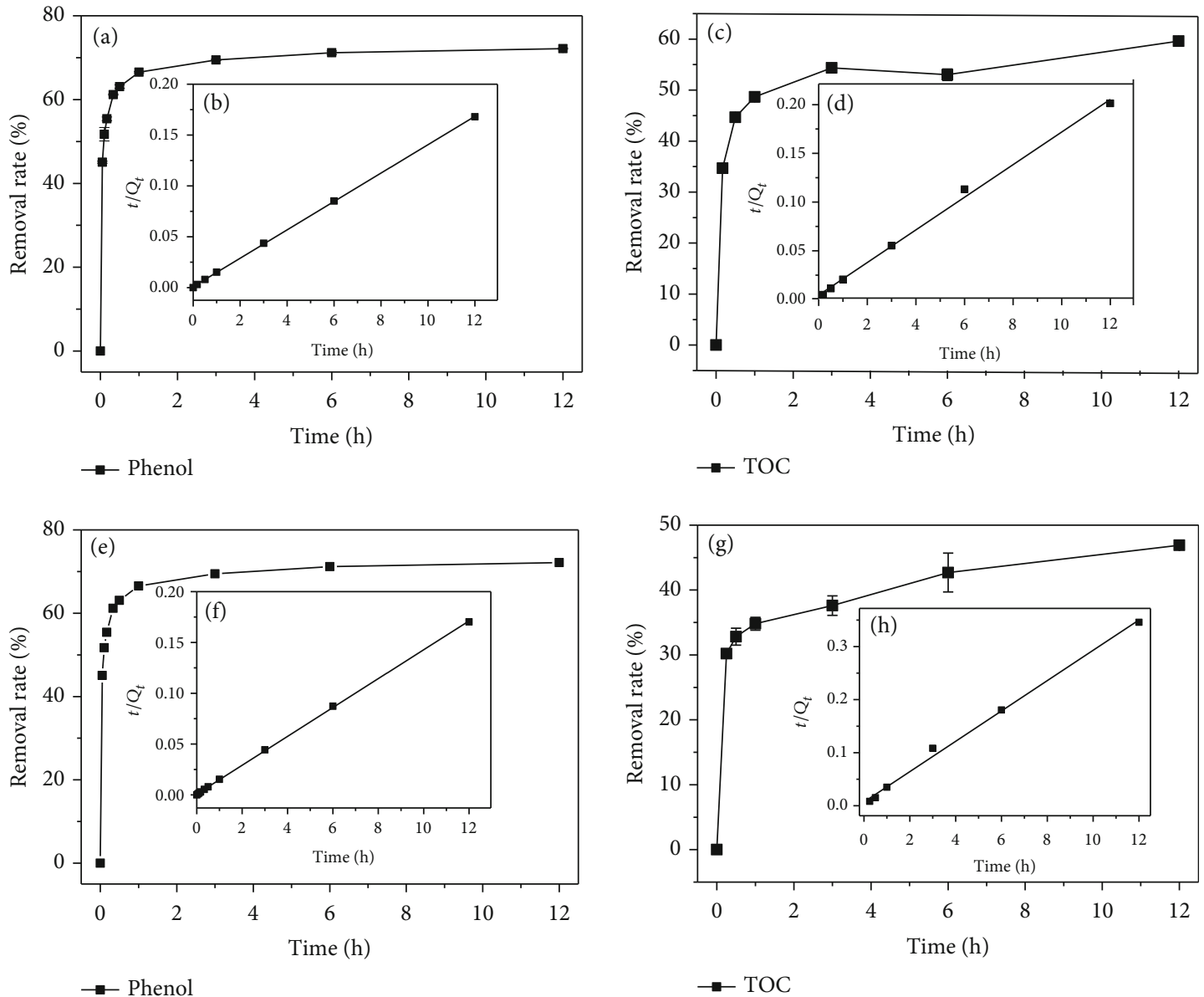

Figure 5: Degradation rates of phenol and TOC (Ver-H (a,c) and Ver-OH (e, g)) and pseudo-second-order kinetic fitting spectra (Ver-H (b, d) and Ver-OH $(f, h))$.

that of phenol, with rapid degradation in the early stage and a slow increase in the later stage.

The pseudo-second-order kinetic fitting parameters for the degradation of phenol and TOC by Ver-H and Ver-OH are shown in Table 2 . The results show that the phenol degradation amount and reaction rate constants of Ver- $\mathrm{H}$ and Ver-OH were not significantly different. However, the TOC degradation amount of Ver-H was significantly larger than that of Ver-OH. The equilibrium degradation amounts of TOC are $58.2 \mathrm{mg} / \mathrm{g}$ and $40.0 \mathrm{mg} / \mathrm{g}$ for Ver-H and Ver-OH, respectively, indicating a $31.3 \%$ increase for Ver-H compared to that for Ver-OH. This indicates that both synthesized vernadites have strong phenol removal ability and that the vernadite synthesized by the new method has better TOC degradation ability. Generally, higher $\mathrm{Mn}_{\mathrm{AOS}}$ values correspond to stronger mineral oxidation capacities [29]. However, the Ver-H Mn $\mathrm{MOS}_{\mathrm{AOS}}$ was smaller than that of Ver-OH,
TABle 2: Pseudo-second-order kinetic parameters for the degradation of phenol and TOC by vernadite.

\begin{tabular}{lccc}
\hline Reaction kinetics & $k_{2}$ & $q_{e}(\mathrm{mg} / \mathrm{g})$ & $R^{2}$ \\
\hline Phenol degradation by Ver-H & 0.2426 & 71.6 & 0.9999 \\
Phenol degradation by Ver-OH & 0.2446 & 70.7 & 0.9998 \\
TOC degradation by Ver-H & 0.1272 & 58.2 & 0.9980 \\
TOC degradation by Ver-OH & 0.1356 & 40.0 & 0.9979 \\
\hline
\end{tabular}

and there was no significant difference in the phenol degradation amount in this study. This may be because, while Ver- $\mathrm{OH}$ has more $\mathrm{Mn}$ than Ver-H and thus a higher $\mathrm{Mn}_{\mathrm{AOS}}$, the $\mathrm{Mn}$ in it is mostly lower-valence Mn(III). Relatively more $\mathrm{Mn}(\mathrm{IV})$ is present in Ver-H; therefore, no significant difference appeared in the phenol removal capacity between Ver$\mathrm{H}$ and Ver-OH. In contrast, the higher TOC degradation 


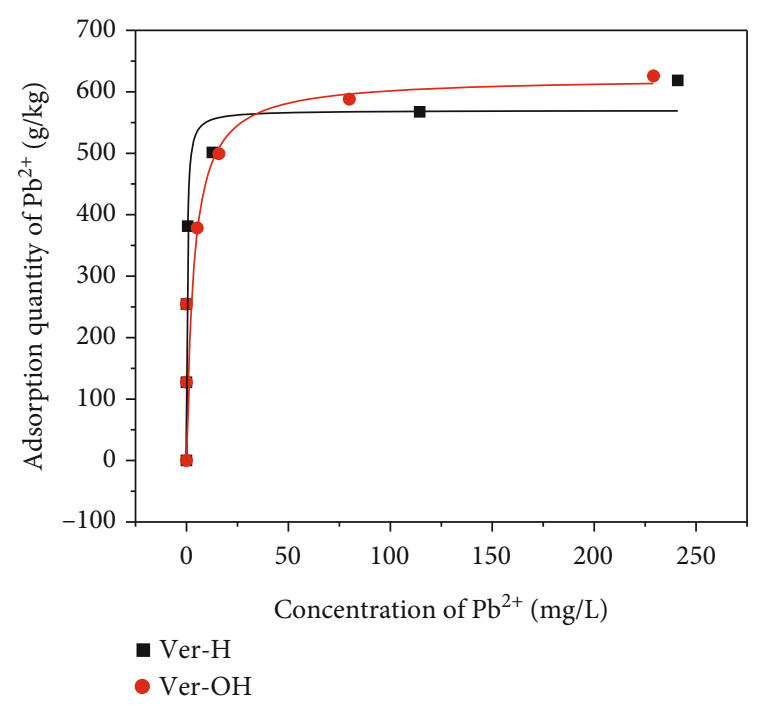

FIGURE 6: Langmuir model adsorption isotherms of vernadite for $\mathrm{Pb}^{2+}$.

TABLE 3: Relevant parameters of $\mathrm{Pb}^{2+}$ isothermal adsorption on vernadite by Langmuir equation fitting.

\begin{tabular}{lccc}
\hline Sample name & $A(\mathrm{~g} / \mathrm{kg})$ & $K$ & $R^{2}$ \\
\hline Ver-H & 569.79 & 2.97 & 0.9011 \\
Ver-OH & 623.10 & 0.28 & 0.9900 \\
\hline
\end{tabular}

amount in Ver-H may be due to its higher content of $\mathrm{Mn}(\mathrm{IV})$ oxygen vacancies [30], thus facilitating the removal of intermediate products formed during phenol degradation. In addition, Ver-H has larger SSAs, which increases the number of surface active sites that can absorb more intermediate products, thereby facilitating their mineralization into $\mathrm{CO}_{2}$. In summary, both Ver-H and Ver-OH show strong phenol degradation performances; however, Ver-H has a better degradation effect on TOC and stronger mineralization ability.

3.7. Lead Adsorption Performance. The isothermal adsorption curves of $\mathrm{Pb}^{2+}$ on the two vernadite samples are shown in Figure 6; both curves are L-shaped. For a low equilibrium concentration of $\mathrm{Pb}^{2+}$, the adsorption amount increases rapidly with increasing $\mathrm{Pb}^{2+}$ concentration and tends to stabilize as the concentration approaches a certain value. The correlation parameters obtained using the Langmuir equation are shown in Table 3 , and the correlation coefficients $R^{2}$ are 0.9011 and 0.9900 , respectively, indicating that the adsorption kinetics of $\mathrm{Pb}^{2+}$ by the two vernadites is consistent with the Langmuir isothermal adsorption model. The maximum adsorption capacities $A$ of Ver-H and Ver-OH are $569.79 \mathrm{~g} / \mathrm{kg}$ and $623.10 \mathrm{~g} / \mathrm{kg}$, respectively, showing that the adsorption capacity of Ver$\mathrm{OH}$ for $\mathrm{Pb}^{2+}$ is slightly larger than that of Ver-H. In general, the adsorption performance of Mn oxide minerals for heavy metal ions is positively correlated with the SSAs; however, related studies have shown that $\mathrm{Mn}_{\mathrm{AOS}}$ also affects the heavy metal adsorption performance and that higher $\mathrm{Mn}_{\mathrm{AOS}}$ values correspond to stronger adsorption capacities [31-33]. This indicates that the $\mathrm{Mn}_{\mathrm{AOS}}$ of vernadites is decisive in determining the $\mathrm{Pb}^{2+}$ adsorption in this study; thus, the $\mathrm{Pb}^{2+}$ adsorption capacity of Ver-OH is slightly higher than that of Ver-H.

\section{Conclusion}

In this study, phase-pure vernadite was successfully synthesized by oxidizing $\mathrm{H}_{2} \mathrm{O}_{2}$ with $\mathrm{KMnO}_{4}$ under dilute acid conditions. Compared to the traditional method, the new method consumes a small amount of concentrated sulfuric acid instead of a large amount of sodium hydroxide; this method is simpler, economical, and environmentally friendly. Moreover, the vernadite synthesized using the new method has a larger particle size and SSAs. The vernadite types synthesized by the two methods both have strong phenol degradation abilities with the degradation amounts of $71.6 \mathrm{mg} / \mathrm{g}$ and $70.2 \mathrm{mg} / \mathrm{g}$, respectively. The kinetic fitting results show that the TOC degradation amount of Ver-H $(58.2 \mathrm{mg} / \mathrm{g})$ is significantly larger than that of Ver-OH $(40.0 \mathrm{mg} / \mathrm{g})$, an increase of $31.3 \%$. Therefore, the vernadite synthesized by the new method has a stronger ability to mineralize organic matter. The adsorptions of $\mathrm{Pb}^{2+}$ by Ver-H and Ver-OH are both consistent with Langmuir isothermal adsorption, and the maximum adsorption capacities are $569.79 \mathrm{~g} / \mathrm{kg}$ and $623.10 \mathrm{~g} / \mathrm{kg}$, respectively. The lack of significant difference indicates that both vernadites have strong adsorption capacities for $\mathrm{Pb}^{2+}$.

\section{Data Availability}

The [DATA TYPE] data used to support the findings of this study are included within the article.

\section{Conflicts of Interest}

The authors declared no potential conflicts of interest with respect to the research, authorship, and/or publication of this article.

\section{Acknowledgments}

The authors disclosed receipt of the following financial support for the research, authorship, and/or publication of this article: this work is financially supported by the National Natural Science Foundation of China (41867004) and Jiangxi Province Graduate Student Innovation Special Fund Project (YC2020-S256), which are gratefully acknowledged

\section{References}

[1] J. S. Bao, J. M. Chen, G. L. Wang et al., "Preparation and electrochemical performance of manganese oxide hexagonal flakes," Bulletin of the Chinese Ceramic Society, vol. 38, no. 4, pp. 1002-1005, 2019.

[2] K. A. Barrett and M. B. Mcbride, "Oxidative degradation of glyphosate and aminomethylphosphonate by manganese 
oxide," Environmental Science \& Technology, vol. 39, no. 23, pp. 3-8, 2005.

[3] S. H. Jee and S. O. Ko, "Application of manganese oxide for the oxidative degradation of bisphenol-A in aqueous phase," Journal of Korean Society on Water Environment, vol. 23, no. 5, pp. 659-664, 2007.

[4] T. A. Sibel, A. Sevcin, and A. Tamer, "Conversion of natural mineral to effective geosorbent by coating $\mathrm{MnO}_{2}$ and its application potential for dye contaminated wastewaters," Journal of Cleaner Production, vol. 189, no. 4, pp. 887897, 2018.

[5] L. M. Zhai, The adsorption of heavy metals by manganese minerals and the mechanism of the influence of $\mathrm{pH}$ on the oxidation of Cr(III) by manganese minerals, Huazhong Agricultural University, 2004.

[6] W. Zhao, F. Liu, X. H. Feng, W. Tan, G. Qiu, and X. Chen, "Fourier transform infrared spectroscopy study of acid birnessites before and after $\mathrm{Pb}^{2+}$ adsorption," Clay Minerals, vol. 47, no. 2, pp. 191-204, 2012.

[7] X. H. Feng, Synthesis, transformation and surface chemical properties of several common manganese oxide minerals, Huazhong Agricultural University, 2004.

[8] F. Gabriela, W. Bernhard, and M. Alain, "Solid phases in the cycling of manganese in eutrophic lakes: new insights from EXAFS spectroscopy," Geochimica et Cosmochimica Acta, vol. 61, no. 2, pp. 275-290, 1997.

[9] S. Grangeon, A. Manceau, J. Guilhermet, A. C. Gaillot, M. Lanson, and B. Lanson, "Zn sorption modifies dynamically the layer and interlayer structure of vernadite," Geochimica et Cosmochimica Acta, vol. 85, no. 2, pp. 302-313, 2012.

[10] S. Zhang, S. F. Chen, F. Liu et al., "Effects of Mn average oxidation state on the oxidation behaviors of $\mathrm{As}$ (III) and $\mathrm{Cr}$ (III) by vernadite," Applied Geochemistry, vol. 94, no. 5, pp. 35-45, 2018.

[11] D. O. Zixuan, L. I. Xinying, J. I. Yonghai et al., "Influencing factors and mechanism of vernadite removal of phenol in groundwater," Environmental Engineering Science, vol. 11, no. 8, pp. 4481-4488, 2017.

[12] K. W. Mandernack, M. L. Fogel, B. M. Tebo, and A. Usui, "Oxygen isotope analyses of chemically and microbially produced manganese oxides and manganates," Geochimica et Cosmochimica Acta, vol. 59, no. 21, pp. 4409-4425, 1995.

[13] J. Luo, Q. Zhang, and S. L. Suib, "Mechanistic and kinetic studies of crystallization of birnessite," Inorganic Chemistry, vol. 39, no. 4, pp. 741-747, 2000.

[14] M. Villalobos, B. Toner, J. Bargar, and G. Sposito, "Characterization of the manganese oxide produced by _pseudomonas putida_strain MnB1," Geochimica et Cosmochimica Acta, vol. 67, no. 14, pp. 2649-2662, 2003.

[15] J. G. Catts and D. Langmuir, "Adsorption of $\mathrm{Cu}, \mathrm{Pb}$ and $\mathrm{Zn}$ by $\hat{\mathrm{I}}^{\prime} \mathrm{MnO}_{2}$ : applicability of the site binding-surface complexation model," Pergamon, vol. 1, no. 2, pp. 255-264, 1986.

[16] J. Luo and S. L. Suib, "Preparative parameters, magnesium effects, and anion effects in the crystallization of birnessites," The Journal of Physical Chemistry B, vol. 101, no. 49, pp. 10403-10413, 1997.

[17] A. D. Victor, L. Bruno, and C. G. Anne, "Birnessite polytype systematics and identiP cation by powder X-ray diffraction," American Mineralogist, vol. 92, no. 5-6, pp. 771788, 2015.
[18] S. M. Webb, B. M. Tebo, and J. R. Barger, "Structural characterization of biogenic Mn oxides produced in seawater by the marine bacillus sp.strain SG-1," American Mineralogist, vol. 90, no. 8-9, pp. 1342-1357, 2015.

[19] S. J. Bao, B. L. He, Y. Y. Liang, W. J. Zhou, and H. L. Li, “Synthesis and electrochemical characterization of amorphous $\mathrm{MnO}_{2}$ for electrochemical capacitor," Materials Science \& Engineering A, vol. 397, no. 1-2, pp. 305-309, 2005.

[20] A.-C. Gaillot, V. A. Drits, A. Manceau, and B. Lanson, "Structure of the synthetic K-rich phyllomanganate birnessite obtained by high- temperature decomposition of $\mathrm{KMnO}_{4}$ :", Microporous and Mesoporous Materials, vol. 98, no. 1-3, pp. 267-282, 2007.

[21] J. Marugán, J. A. Botas, M. Martín, R. Molina, and C. Herradón, "Study of the first step of the $\mathrm{Mn}_{2} \mathrm{O}_{3} / \mathrm{MnO}$ thermochemical cycle for solar hydrogen production," International Journal of Hydrogen Energy, vol. 37, no. 8, pp. 70177025, 2012.

[22] A. C. Marcos, K. B. Pradip, S. Z. Qian, S. W. Joo, W. Hou, and J. M. Okoh, "A new method of synthesizing black birnessite nanoparticles: from brown to black birnessite with nanostructures," Journal of Nanomaterials, vol. 2008, no. 3, Article ID 763706, 726 pages, 2008.

[23] W. Zhao, W. F. Tan, M. X. Wang et al., "CD-MUSIC-EDL modeling of $\mathrm{Pb}^{2+}$ adsorption on birnessites: role of vacant and edge sites," Environmental Science \& Technology, vol. 52, no. 18, pp. 10522-10531, 2018.

[24] C. M. Julien, M. Massot, and C. Poinsignon, "Lattice vibrations of manganese oxides: Part I. Periodic structures," Spectrochimica acta Part A, Molecular and biomolecular spectroscopy, vol. 60, no. 3, pp. 689-700, 2004.

[25] R. P. Liu, H. J. Liu, Z. M. Qiang, J. Qu, G. Li, and D. Wang, "Effects of calcium ions on surface characteristics and adsorptive properties of hydrous manganese dioxide," Journal of Colloid and Interface Science, vol. 331, no. 2, pp. 275-280, 2009.

[26] F. T. Ling, J. E. Post, P. J. Heaney, J. D. Kubicki, and C. M. Santelli, "Fourier-transform infrared spectroscopy (FTIR) analysis of triclinic and hexagonal birnessites," Spectrochimica Acta Part A: Molecular and Biomolecular Spectroscopy, vol. 178, no. 2, pp. 32-46, 2017.

[27] Y. Guan, X. M. Sun, X. D. Jiang et al., "The effect of Fe-Mn minerals and seawater interface and enrichment mechanism of ore-forming elements of polymetallic crusts and nodules from the South China Sea," Acta Oceanologica Sinica, vol. 36, no. 6, pp. 34-46, 2017.

[28] Y. Luo, L. H. Liu, Z. H. Jia, W. F. Tan, F. Liu, and G. H. Qiu, "The effect of Mn AOS on the supercapacitor performance of birnessite," Functional Materials, vol. 47, no. 7, pp. 71877191, 2016.

[29] J. L. Xu, F. Zhang, F. Liu, W. F. Tan, G. H. Qiu, and X. H. Feng, "Kinetic of As(III) and $\mathrm{Cr}$ (III) oxidation by alkaline birnessites with various average Mn oxidation states," Journal of Rock and Mineralogy, vol. 32, no. 6, pp. 975-984, 2013.

[30] M. Q. Zhu, K. W. Paul, J. D. Kubicki, and D. L. Sparks, "Quantum chemical study of arsenic (III, V) adsorption on Mnoxides: implications for arsenic (III) oxidation," Environmental Science \& Technology, vol. 43, no. 17, pp. 66556661, 2009.

[31] Y. Wang, X. H. Feng, M. Villalobos, W. Tan, and F. Liu, "Sorption behavior of heavy metals on birnessite: relationship with its Mn average oxidation state and implications for types of 
sorption sites," Chemical Geology, vol. 292-293, pp. 25-34, 2012.

[32] Y. Wang, W. F. Tan, X. H. Feng, G. H. Qiu, and F. Liu, "Adsorption of several heavy metal ions by birnessite and its relationship with oxidation degree and adsorption sites of manganese," Environmental Science, vol. 32, no. 10, pp. 3128-3136, 2011.

[33] J. H. Zhao, Z. W. Zhao, N. Li, J. Nan, R. Yu, and J. du, "Visiblelight-driven photocatalytic degradation of ciprofloxacin by a ternary $\mathrm{Mn}_{2} \mathrm{O}_{3} / \mathrm{Mn}_{3} \mathrm{O}_{4} / \mathrm{MnO}_{2}$ valence state heterojunction," Chemical Engineering Journal, vol. 353, no. 5, pp. 805-813, 2018. 